\title{
Sorption of Nickel and Cobalt on a Size-Fraction of Unconsolidated Glaciofluvial Deposits and on Clay Minerals
}

\author{
By A. Grütter, H. R. von Gunten, E. Rössler and R. Keil \\ Paul Scherrer Institut, CH-5232 Villigen PSI, Switzerland
}

(Received March 10, 1994; revised May 4, 1994)

\section{Sorption / Nickel / Cobalt / Glaciofluvial deposits / Clay minerals / Cesium / Strontium / Barium}

\begin{abstract}
In earlier studies we investigated the sorption behaviour of cesium, barium and strontium on size fractions of glaciofluvial materials and on the clay minerals montmorillonite, illite and chlorite. Here, we report on sorption and desorption experiments with nickel and cobalt in synthetic groundwater on the $<32 \mu \mathrm{m}$ size-fraction of a glaciofluvial deposit, on the clay minerals montmorillonite and illite, and on synthetic $\mathrm{SiO}_{2}$ and $\mathrm{CaCO}_{3}$. In general, sorption and desorption equilibrium is not reached for nickel and cobalt, which is in striking contrast to the behaviour observed for strontium and barium. A significant increase in the distribution ratios was observed for nickel and cobalt up to sorption times of 182 and 56 days, respectively. In most cases, the sorption process was largely irreversible. The sorptive power of the $<32 \mu \mathrm{m}$ materials with artificially changed mineralogies is considerably reduced as compared to that of the $<32 \mu \mathrm{m}$ material with the original mineralogical composition, i. e., during the removal of the carbonates a significant decrease in the sorptive power occurred. A comparison of the sorption behaviour of nickel and cobalt with that of cesium, strontium and barium is also shown.
\end{abstract}

\section{Introduction}

The radiation hazard of the activation product ${ }^{59} \mathrm{Ni}$ (half life: 75000 years) is taken into account in estimates for nuclear waste repositories [e. g. 1]. The environmental behaviour of nickel ions is only poorly known and no data are available about its migration in glaciofluvial deposits. Quaternary glaciofluvial materials were selected for the present investigation, since such deposits abound in pre-alpine countries and act as the final barrier before radionuclides released from an underground storage facility enter the biosphere. The glaciofluvial deposits consist of gravel, sand, silt and clay. The clay minerals montmorillonite and illite, and synthetic $\mathrm{SiO}_{2}$ and $\mathrm{CaCO}_{3}$ are included in our studies for comparative purposes. Clay minerals are constituents of glaciofluvial materials, are powerful sorbents and will be used as back-fill materials in nuclear waste repositories.

Cobalt was investigated mainly because unexpected effects were observed for the sorption of nickel. Under our experimental conditions, cobalt and nickel form stable solutions of soluble compounds up to concentrations of $100 \mu \mathrm{mol} / \mathrm{l}$.
In the literature sorption isotherms are presented in Refs. [2, 3] for nickel and in Refs. [2-6] for cobalt. The results were obtained on widely varying solid materials and under very different conditions and do not allow to draw conclusions of general validity even with respect to the shape of the isotherms: nearly linear isotherms are reported in [2,3], whereas isotherms of the Freundlich type are shown in [6] and composite ones in $[4,5]$.

\section{Experimental}

\section{Materials}

The glaciofluvial materials were obtained from the water-saturated part of a percussion drilled core at Glattfelden ( $20 \mathrm{~km}$ north of Zürich). This material had been deposited by the Rhine glacier during the ice ages and was subsequently rearranged by rivers. The $<32 \mu \mathrm{m}$ size fraction was isolated by wet-sieving from the section of the core which was situated 22 to $24 \mathrm{~m}$ below the surface. Its mineralogical composition was: $31 \%$ quartz, $36 \%$ calcite, $7 \%$ dolomite, $11 \%$ albite, $9 \%$ illite, $5 \%$ chlorite and $1 \%$ montmorillonite (Tj. Peters, private communication). Experiments were performed with $<32 \mu \mathrm{m}$ material treated

- with $1 \mathrm{M} \mathrm{NaCl}$ solutions in order to reduce the amounts of interfering cations present at low concentrations.

- to remove carbonates, then free iron and manganese (hydr)oxides, and finally organic compounds. [7].

For details concerning these treatments see Ref.

Experiments were also conducted with a montmorillonite from Crook County, Wyoming, USA and an illite from Puy-en-Velay, France. In addition, the sorption of nickel was also investigated on two synthetic $\mathrm{SiO}_{2}$ powders (Johnson Matthey Alpha Products 400251: crystalline $99.999 \%$ and 88316: <325 mesh, $99.9 \%$ ), and the sorption of nickel and cobalt on $\mathrm{CaCO}_{3}$ (Merck product No. 2066). These materials were used as obtained from the suppliers.

The cation-exchange capacities $\mathrm{C}$ were determined by sodium saturation in $1 \mathrm{M}$ sodium acetate (procedure of Chapman [8], adapted for small samples using Na-22). The results were summarized in Table 1 of Ref. [7]. 


\section{Synthetic groundwater}

All experiments were performed with synthetic groundwater (SGW) of the following composition (in meq/1): $\mathrm{Ca}^{2+}, 4.50 ; \mathrm{Mg}^{2+}, 1.69 ; \mathrm{Na}^{+}, 0.67 ; \mathrm{K}^{+}, 0.084$; $\mathrm{Cl}^{-}, 6.52$; alkalinity, $0.42 ; \mathrm{pH}, 7.9$. This composition is typical for groundwaters of calcite-rich aquifers, except for $\mathrm{HCO}_{3}^{-}$which was largely replaced by the chloride ion to allow investigations at ambient $\mathrm{CO}_{2}$ pressure. This synthetic groundwater is slightly undersaturated with respect to calcite.

\section{Procedure and calculations}

In a batch method $200 \mathrm{mg}$ of solid material were contacted with $30 \mathrm{ml}$ of synthetic groundwater in a closed 40-ml centrifuge tube. The tubes were turned headover-end at $1 \mathrm{rpm}$. The solid material remained within this tube throughout the sequence: (1) equilibration with synthetic groundwater, (2) sorption, (3) desorption and (4) treatment with $1 \mathrm{M} \mathrm{HCl}$. For the sorption experiment, either ${ }^{63} \mathrm{Ni}$ - or ${ }^{57} \mathrm{Co}$-tracer was added to the synthetic groundwater. The tracers were obtained from Amersham (England). Concentrations up to $100 \mu \mathrm{mol} / /$ were achieved by adding appropriate amounts of nickel or cobalt chloride. The procedure is described in more detail in Ref. [7]. The duration of the sorption and desorption experiment was 56 days for cobalt and in most cases 182 days for nickel. To follow the time dependence of sorption and desorption, one of the parallel samples was centrifuged from time to time. After each interval, a sample of $5 \mathrm{ml}$ was withdrawn in the experiments with cobalt, counted on a Ge-detector and returned to the centrifuge tube. In the case of nickel, a sample of $1 \mathrm{ml}$ was withdrawn, mixed with $10 \mathrm{ml}$ of Insta-Gel cocktail and counted on a liquid scintillation spectrometer. The centrifuge tubes were weighed to determine the losses of liquid during these operations.

If we denote the concentration of the element under consideration in the solid material by $\left[\mathrm{Me}^{n+}\right]_{s}$ $(\mathrm{mmol} / \mathrm{g})$ and that in solution by $\left[\mathrm{Me}^{n+}\right](\mathrm{mmol} / \mathrm{ml})$, then the distribution ratio is defined by $R_{D}=\left[\mathrm{Me}^{n+}\right]_{s} /$ $\left[\mathrm{Me}^{n+}\right](\mathrm{ml} / \mathrm{g})$ and the loading of the solid material by $\left[\mathrm{Me}^{n+}\right]_{\mathrm{s}}{ }^{*} n / C$. $C$ is the cation exchange capacity in meq/g. The distribution ratios were calculated using equations (1) to (5) in Ref. [9]. Two different approaches were used to evaluate the concentrations of nickel and cobalt in the solutions:

(1) It was assumed that the specific activity, i. e., $\mathrm{Bq} / \mathrm{g}$ of ${ }^{63} \mathrm{Ni}$ or ${ }^{57} \mathrm{Co}$, remained unchanged during the experiment and the concentrations were calculated from the measured radioactivities of ${ }^{63} \mathrm{Ni}$ and ${ }^{57} \mathrm{Co}$; this yields the lowest possible concentrations, since contributions of inactive nickel or cobalt originating from the solid are not taken into account.

(2) At the end of the sorption and desorption experiment the concentrations of nickel and cobalt were determined in the solutions using ICP-AES. However, the lowest concentrations were below the
Table 1. Speciation of nickel and cobalt ions in solution. The first value in the given range refers to synthetic groundwater and a nickel or cobalt concentration of $100 \mu \mathrm{mol} / \mathrm{l}$, the second, which is independent of concentration, to synthetic groundwater saturated with calcite.

The following $\mathrm{pK}$-values were used in the calculations:

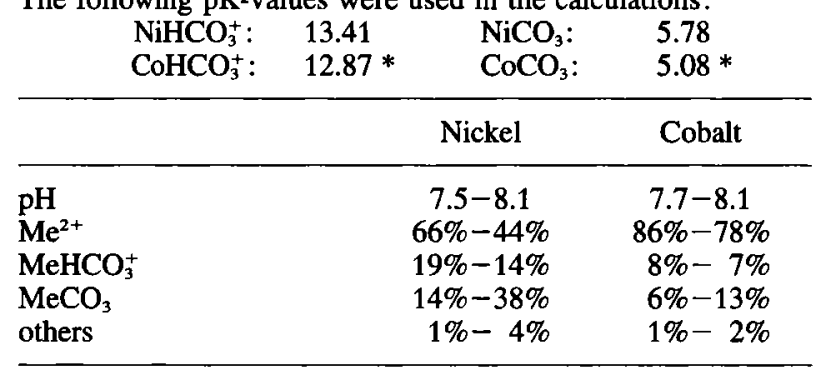

* extrapolated value, see text

detection limit of $0.01 \mu \mathrm{mol} / \mathrm{l}$. In these cases the concentrations were calculated using the specific activities of ${ }^{63} \mathrm{Ni}$ or ${ }^{57} \mathrm{Co}$ determined in extracts obtained by treating the solid materials with $1 \mathrm{M} \mathrm{HCl}$ at the end of the experiments. The amount of tracer desorbed during this treatment amounted to $\geq 94 \%$ for nickel and cobalt. The concentrations of nickel or cobalt based on the specific activities in the $\mathrm{HCl}$-extracts represent upper limits, since nickel and cobalt initially present in the solid materials, but not involved in the sorption process, may have been dissolved by $\mathrm{HCl}$.

The geochemical computer code PHREEQUE [10] was used to calculate the formation of complexes of nickel and cobalt ions in the synthetic groundwater. The results are presented in Table 1 . The formation constants for the carbonato-complexes are also given. Since no values were available for cobalt, the means of the $\mathrm{pK}$-values for iron and nickel, the two elements adjacent to cobalt in the periodic table, were used as a rough and possibly somewhat erraneous approximation.

\section{Results and discussion}

Time dependence of sorption and desorption

The evolution of the distribution ratios $\left(R_{D}\right)$ for nickel and cobalt with time is shown in Fig. 1 for the clay minerals montmorillonite and illite and in Fig. 2 for two of the $<32 \mu \mathrm{m}$ materials, namely the NaCl-treated material and the material "free" of carbonates, oxides and organics. The time dependence of the two $<32 \mu \mathrm{m}$ materials not shown in Fig. 2, i. e., that free of carbonates, and that free of carbonates and oxides, resembled the behaviour of the $<32 \mu \mathrm{m}$ material free of carbonates, oxides and organics. The counting rates for the samples with initial concentrations of $100 \mu \mathrm{mol} / 1$ of nickel and $1 \mu \mathrm{mol} / \mathrm{l}$ of cobalt were too low in the case of the $\mathrm{NaCl}$-treated $<32 \mu \mathrm{m}$ material to yield meaningful results in the desorption experiments. The variations in the data for the desorption of nickel from the $\mathrm{NaCl}$-treated $<32 \mu \mathrm{m}$ material are also due to low counting rates. 

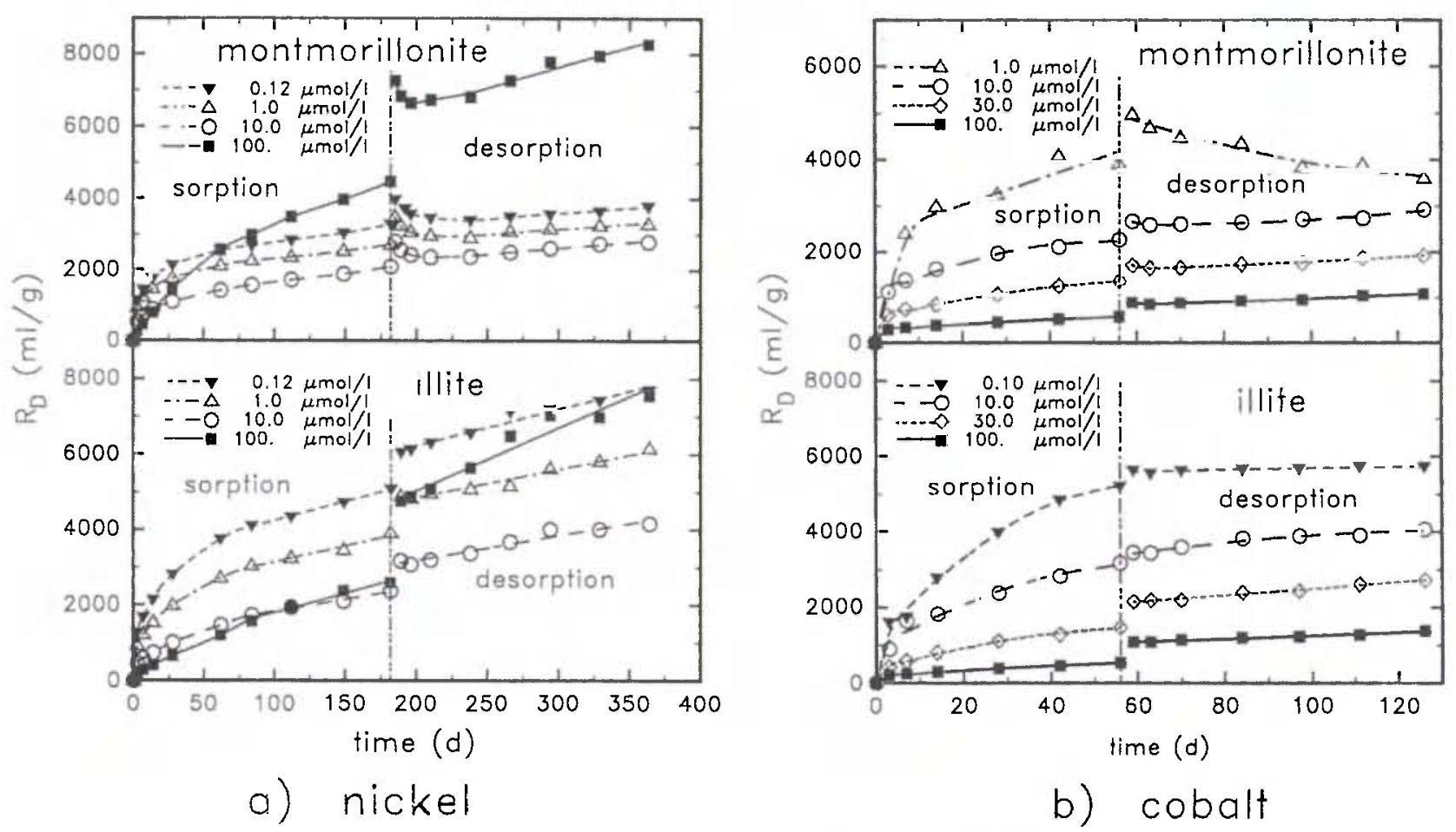

Fig. 1. Time dependence of sorption and desorption of nickel and cobalt at different concentrations on the clay minerals montmorillonite and illite. The samples are characterized by the initial nickel or cobalt concentration in the sorption solution.
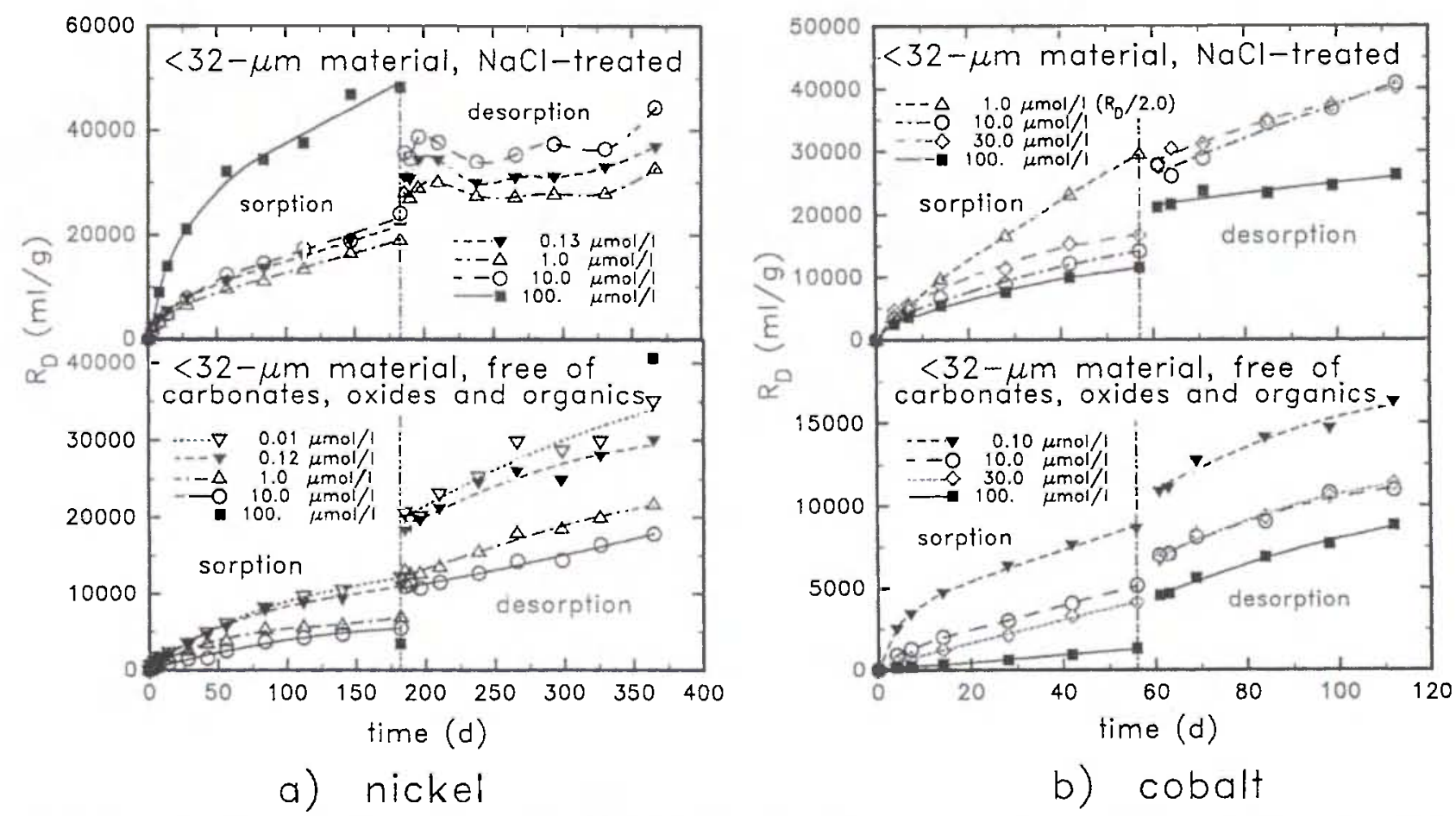

Fig. 2. Time dependence of sorption and desorption of nickel and cobalt at different concentrations on $<32 \mu \mathrm{m}$ glaciofluvial materials. The samples are characterized by the initial nickel or cobalt concentration in the sorption solution.

From Figs. 1 and 2 it is evident, that equilibrium was not reached during the sorption experiment (182 days duration for nickel and 56 days for cobalt). At initial nickel concentrations of $100 \mu \mathrm{mol} / 1$ unexpected high sorption rates were observed for the montmorillonite, the illite and the $\mathrm{NaCl}$-treated $<32 \mu \mathrm{m}$ materi- al. Such an effect was neither observed for the sorption of nickel on the $<32 \mu \mathrm{m}$ materials with changed mineralogy nor for the sorption of cobalt on any of the materials investigated.

During the desorption experiment the distribution ratios continue to increase, sometimes after an initial 


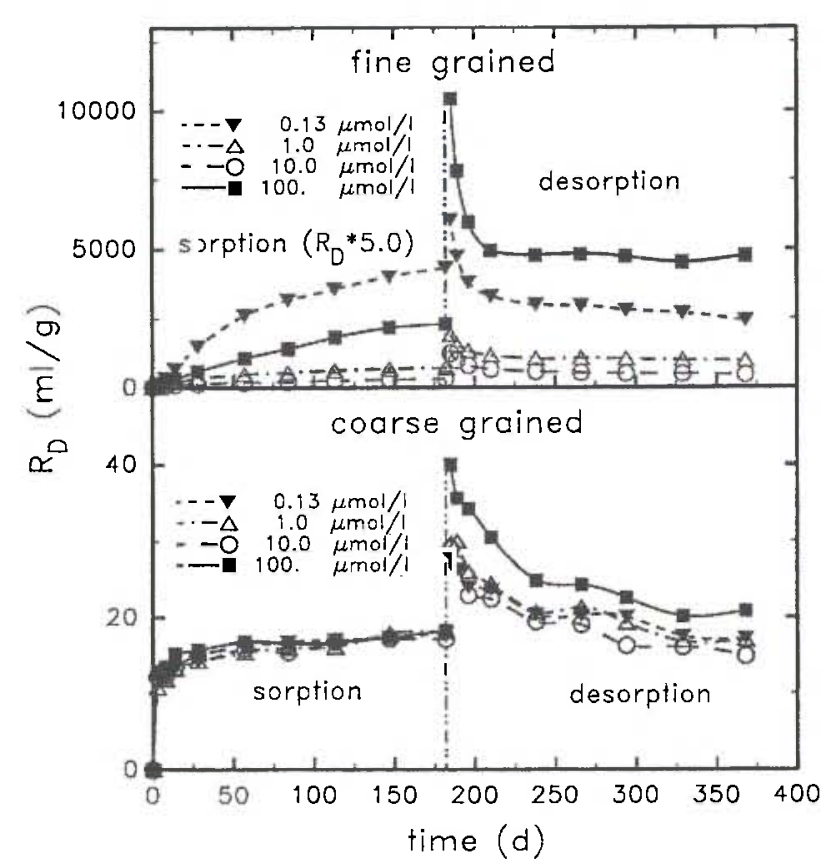

Fig. 3. Time dependence of sorption and desorption of nickel at different concentrations on two synthetic $\mathrm{SiO}_{2}$ powders of different grain-size. The samples are characterized by the initial nickel concentration in the sorption solution.

decrease, i. e. the tracer continues to be sorbed. Deviations from this behaviour were only detected in the experiments with cobalt on montmorillonite and illite at the lowest concentration. By far the largest increase in the distribution ratios was observed at an initial nickel concentration of $100 \mu \mathrm{mol} / 1$ for all materials, even for the $<32 \mu \mathrm{m}$ materials with changed mineralogy. The desorption data, extrapolated to the beginning of the desorption experiments, are in most cases distinctly higher than the distribution ratios at the end of the sorption experiments. This indicates that considerable amounts of sorbed tracer do not particpate in the processes occuring during the desorption experiments, i. e., are irreversibly sorbed.

Experiments with nickel were also performed on two synthetic $\mathrm{SiO}_{2}$ powders. The results are shown in Fig. 3. For the fine grained $\mathrm{SiO}_{2}$ a behaviour similar to the other materials is observed: the $R_{D}$-values for sorption continue to increase up to 182 days. The $R_{D}$ 's for desorption are much higher than those for sorption (notice different scales for sorption and desorption) demonstrating considerable irreversibilities; moreover at the initial $\mathrm{Ni}$ concentration of $100 \mu \mathrm{mol} / \mathrm{l}$ an enhanced sorption is observed.

For the coarse grained (crystalline) $\mathrm{SiO}_{2}$ the $R_{D^{-}}$ values for sorption are almost constant after 30 days. At the end of desorption the $R_{D}$-values are of the same magnitude as at the end of sorption indicating that irreversibilities are small and are practically independent of the $\mathrm{Ni}$ concentrations; the scatter in the desorption data is due to the experimental uncertainties.

Since the decrease in grain-size between the coarse and fine $\mathrm{SiO}_{2}$ leads not only to increased $R_{D}$-values, but also to a very different sorption behaviour, additional factors must play a role, presumably structural and morphological irregularities. The results with the fine grained $\mathrm{SiO}_{2}$, furthermore, suggest that similar factors may also govern the sorption behaviour on the other materials investigated in this paper.

\section{Sorption and desorption curves}

In Figs. 4-7 the distribution ratios are presented in log-log plots as a function of the loadings of the solid materials with nickel or cobalt. We call the resulting curves "sorption and desorption curves". Since equilibrium was not reached, the positions and shapes of the sorption and desorption curves depend on the time interval chosen. In Figs. 4-7 two sets of data are presented for nickel and cobalt (curves and symbols; for details see "Procedure and calculations"). Non-equilibrium conditions and irreversibilities cause additional uncertainties at low loadings, since it cannot be excluded that the specific activities of the tracers in the solid material differ from those in solution.

The sorption and desorption curves for the clay minerals are presented in Fig. 4 and for two of the $<32 \mu \mathrm{m}$ materials in Fig. 5. Only the curves based on unchanged specific activities are presented for the sorption of nickel at an intermediate time interval of approximately 60 days and for the data on the $<32 \mu \mathrm{m}$ material free of carbonates, oxides and organics, since no experimentally determined concentrations are available.

The sorption and desorption curves for nickel bend upwards at high concentrations; the only exceptions are the sorption curves for the $<32 \mu \mathrm{m}$ materials with changed mineralogy. As already mentioned in the chapter "Time dependence", this strange behaviour of nickel is most likely caused by structural and morphological irregularities. On the other hand, the distribution ratios for cobalt often show a marked decrease at high concentrations. Approaching saturation of the sorption sites could have caused this decrease. The sorption and desorption curves for cobalt on the montmorillonite show an unexpected, pronounced dependence of the distribution ratios on concentration. This contrasts with the behaviour observed in our experiments for all other elements on the montmorillonite (see Fig. 7). The differences between sorption and desorption curves are especially large for the sorption of cobalt at low concentrations on the $\mathrm{NaCl}$-treated $<32 \mu \mathrm{m}$ material. They are lowest for the data of nickel and cobalt on the montmorillonite. The sorption curves for of all $<32 \mu \mathrm{m}$ materials valid at a time interval of approximately 60 days are presented in Fig. 6. To give an idea of the uncertainties at low concentrations of nickel, values based on the specific activities of ${ }^{63} \mathrm{Ni}$ in the $\mathrm{HCl}$-extracts are also shown. The following conclusions can be drawn:

- The NaCl-treated $<32 \mu \mathrm{m}$ material, which has the same mineralogical composition as the original material, shows the highest distribution ratios for 

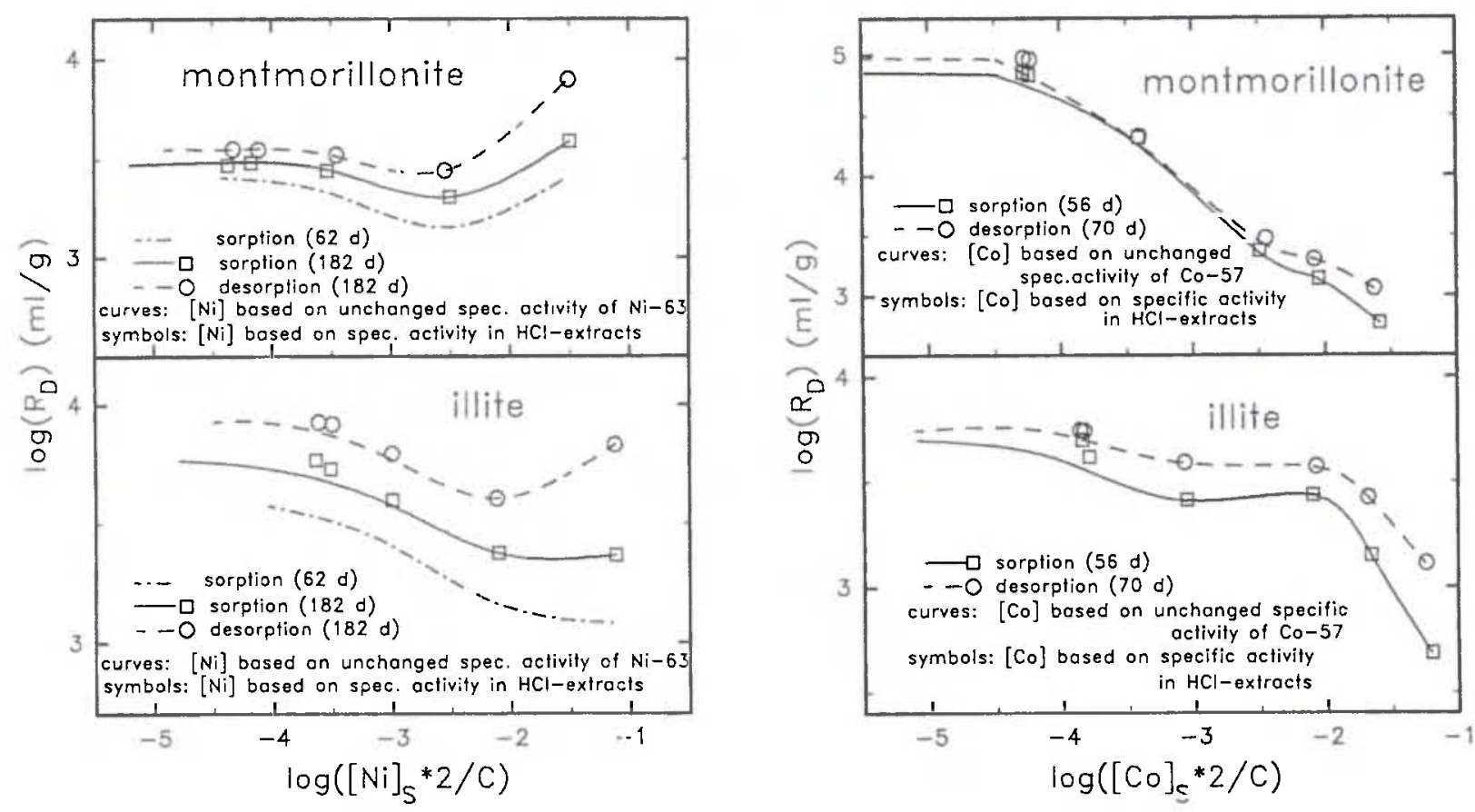

Fig. 4. Sorption and desorption curves for nickel and cobalt obtained for the clay minerals montmorillonite and illite. Curves: concentrations based on the assumption of unchanged specific activities of the tracers. Symbols: experimentally determined concentrations, at low concentrations based on the determined in $\mathrm{HCl}$-extracts (see text).
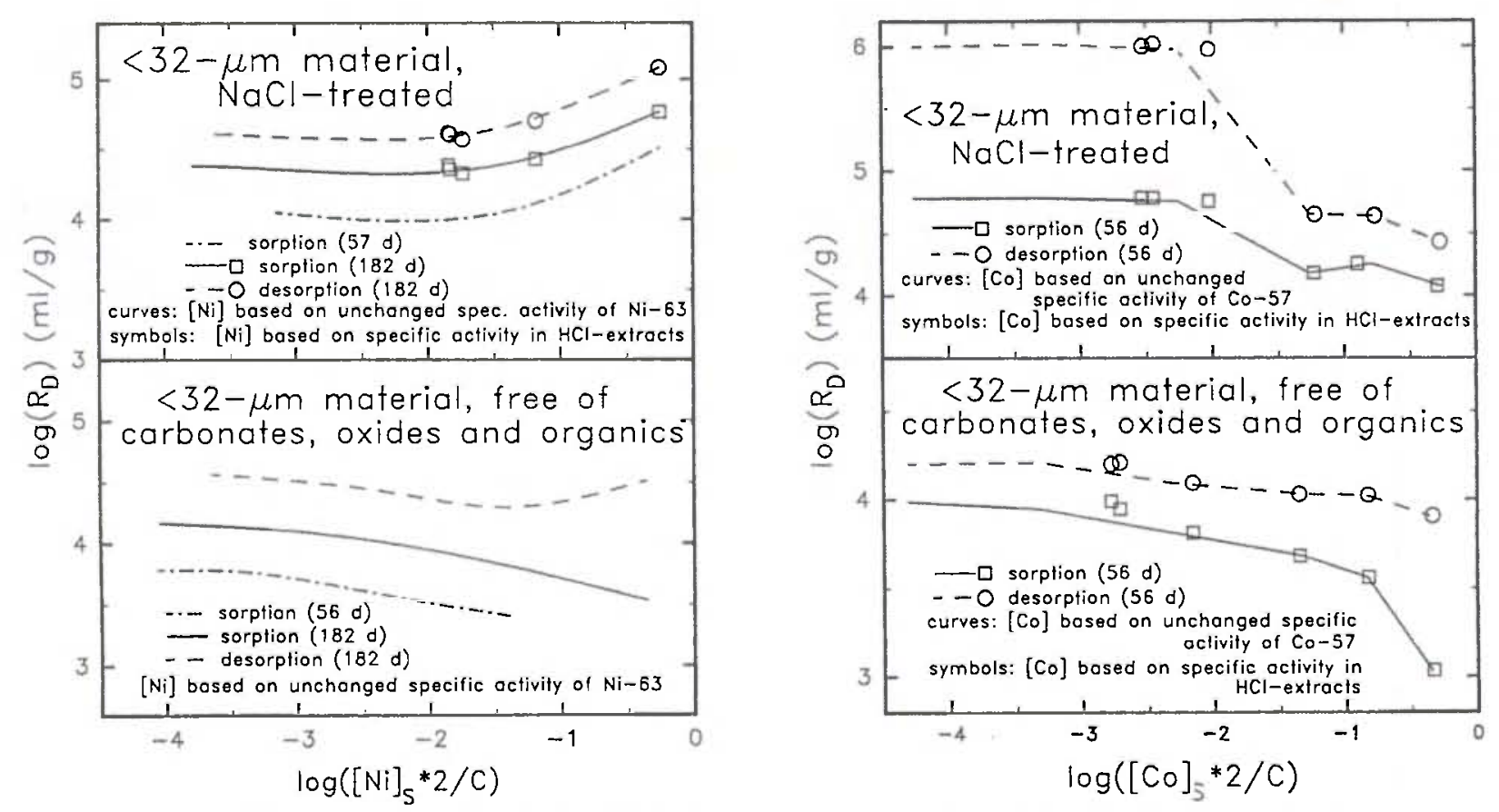

Fig. 5. Sorption and desorption curves for nickel and cobalt obtained for two of the $<32 \mu \mathrm{m}$ glaciofluvial materials. Curves and symbols: for explanation see Fig. 4.

nickel and cobalt. This suggests that the contribution of the carbonates might be significant. However, experiments investigating the sorption of nickel and cobalt on a synthetic calcium carbonate did yield very low distribution ratios (for nickel: $20 \mathrm{ml} / \mathrm{g}$ at [Ni] = $0.095 \mathrm{~mol} / /, 4.8 \mathrm{ml} / \mathrm{g}$ at $[\mathrm{Ni}]=100 \mu \mathrm{mol} / \mathrm{h}$; for cobalt: $28 \mathrm{ml} / \mathrm{g}$ at $[\mathrm{Co}]=0.0087 \mathrm{~mol} / /, 4.7 \mathrm{ml} / \mathrm{g}$ at $[\mathrm{Co}]=$ $95 \mathrm{~mol} / \mathrm{l})$. Therefore, it is more likely, that structural and morphological irregularities with a high affinity to sorb nickel and cobalt disappeared during the removal of the carbonates.

- For both nickel and cobalt the sorption curves for the $<32 \mu \mathrm{m}$ materials with changed mineralogy are similar, as well with respect to the magnitude of the distribution ratios as to the shape of the curves. However, at low concentrations, the curve for the sorp- 


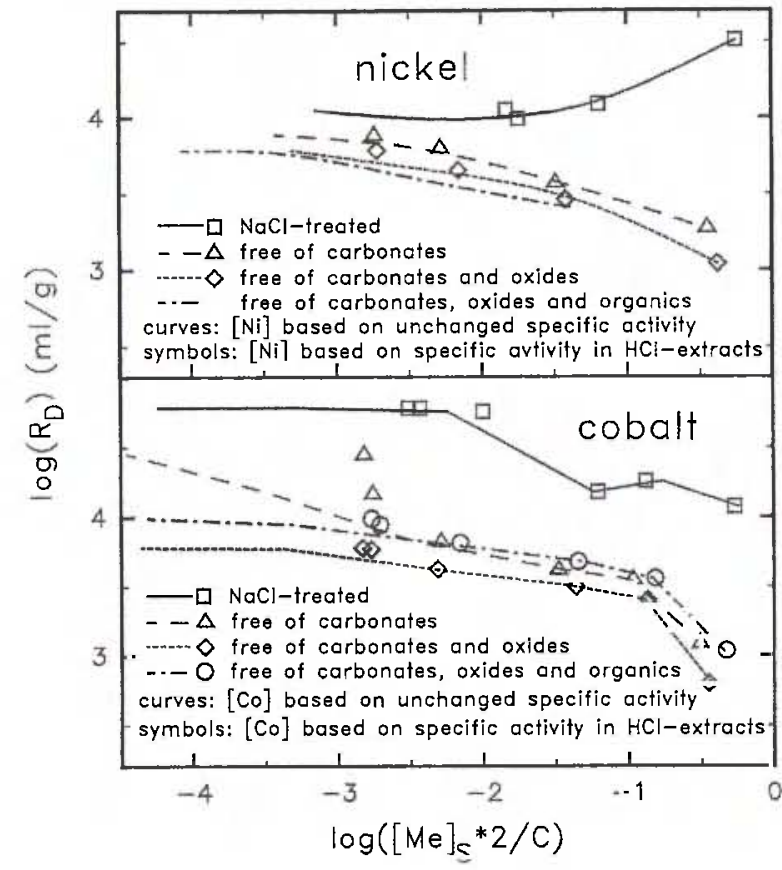

Fig. 6. Influence of changed mineralogy (chemical treatment) on the sorption of nickel and cobalt on all $<32 \mu \mathrm{m}$ glaciofluvial materials. The sorption time is approximately 60 days. Curves and symbols: for explanation see Fig. 4.

tion of cobalt on the $<32 \mu \mathrm{m}$ material free of carbonates is steeper than those for the other $<32 \mu \mathrm{m}$ materials with changed mineralogy. Probably a small fraction of the sorption sites causing the high distribution ratios for the $\mathrm{NaCl}$-treated material are still present in the material free of carbonates. Since this effect is not observed for the data of nickel, these sites have a higher affinity for cobalt than for nickel.

\section{Comparision of the sorption of nickel} and cobalt with that of cesium, strontium and barium

In Fig. 7 the sorption data of the present work for nickel and cobalt are compared with those for cesium [9], strontium [11] and barium [7]. The data for cesium are included for the sake of completeness.

The sorption of the divalent ions strontium and barium can be characterized in the following way: equilibrium was reached within 14 days and the sorption process was reversible on all solid materials. The distribution ratios of both elements on the montmorillonite are almost constant with concentration (linear isotherm) and the distribution ratios are of similar magnitude. For the other materials the isotherms for strontium are also nearly linear, those for barium on the other hand are strongly non-linear with considerably higher distribution ratios than those of strontium. Changes in the mineralogy of the $<32 \mu \mathrm{m}$ materials (removal of the carbonates, oxides or organic substances) affected the sorption curves only slightly. The main process governing the sorption of strontium and

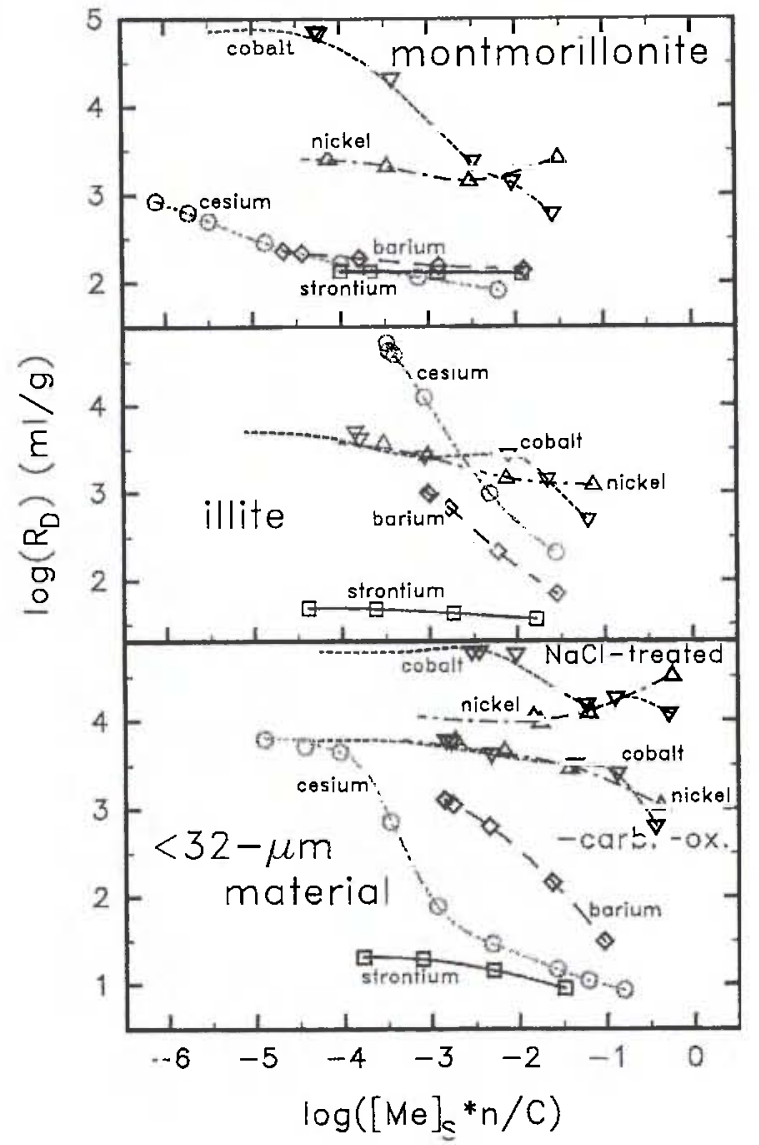

Fig. 7. Data for the sorption of cesium, strontium, barium, cobalt and nickel on montmorillonite, illite and $<32 \mu \mathrm{m}$ glaciofluvial materials. For cobalt and nickel the $<32 \mu \mathrm{m}$ materials with changed mineralogical compositions are represented by the material free of carbonate and oxides (see Fig. 6). The sorption time is approximately 60 days. Curves and symbols: for explanation see Fig. 4.

barium was ion exchange on the clay minerals $[12,13$, 14].

The sorption curves for nickel and cobalt depend on the time interval chosen (in Fig. 7: approximately 60 days), since equilibrium was not reached. The sorption process seems to be largely irreversible. The distribution ratios for nickel and cobalt are distinctly higher than those for strontium and barium. Considerable differences between the sorption curves of nickel and cobalt are only observed for the montmorillonite and the $\mathrm{NaCl}$-treated $<32 \mu \mathrm{m}$ material. Processes other than ion exchange, probably reactions on structural and morphological irregularities of the solid materials, are dominant in the sorption of nickel and cobalt.

The comparison of the isotherms and sorption curves in Fig. 7 for different solid materials evidences very drastic differences for the sorption behaviour of these predominantly divalent (i. e. not sensitive to redox processes) elements. It demonstrates in an impressive way that meaningful predictions for the sorptive and desorptive behaviour and retardation of elements with a relevance for radioactive wastes can only 
be made by careful measurements of isotherms (or sorption curves) with the real host rocks. Therefore big care should be taken to make such predictions as conservative as possible.

\section{Acknowledgements}

The authors acknowledge H. Gäggeler for discussions, the Institute for Aquatic Sciences (EAWAG) and $\mathrm{Tj}$. Peters for supplying some of the materials.

\section{Literature}

1. Nagra NTB 93-26, Beurteilung der Langzeitsicherheit des Endlagers SMA am Standort Wellenberg, Sept. 1993.

2. Cornell, R. M., Aksoyoglu, S.: J. Radioanal. Nucl. Chem., Letters 164, 389 (1992).

3. Legoux, Y., Blain, G., Guillaumont, R., Ouzounian, G., Brillard, L., Hussonnois, M.: Radiochim. Acta 58/59, 211 (1992).

4. Benes, P., Jurak, M., Kuncova, M.: J. Radioanal. Nucl. Chem., Articles, 132, 209 (1989).
5. Polzer, W. L., Fuentes, H. R., Essington, E. H., Roensch, F. R.: Equilibrium Sorption of Cobalt, Cesium and Strontium on Bandelier Tuff: Analysis of Alternative Mathematical Modeling, in: Waste Management '85, Proc. Symp. Waste Management, Tucson, Arizona, Vol. 3, pp. 167-173, (Post, R. G., ed.), 1985.

6. Ohe, T.: Nucl. Technol. 67, 92 (1984).

7. Grütter, A., von Gunten, H. R., Rössler, E.: Radiochim. Acta 58/59, 259 (1992)

8. Chapman, H. D.: Cation-Exchange Capacity by Sodium Saturation, in: Methods of Soil Analysis, Part 2 (Black, C. A., ed.), Am. Soc. Agron. Publ., Madison 1965.

9. Grütter, A., von Gunten, H. R., Kohler, M., Rössler, E.: Radiochim. Acta 50, 177 (1990).

10. Parkhurst, D. L., Thorstenson, D. C., Plummer, L. N.: A computer program for geochemical calculations, NTIS Tech. Rep. PB81 167801 (1980).

11. Grüitter, A., von Gunten, H. R., Rössler, E., Keil, R.: Radiochim. Acta. 64, 247 (1994).

12. Weiss, A., Sextl, E.: Clay Minerals as Ion Exchangers, in: Ion Exchangers (Dorfner, K., ed.), Walter de Gruyter, Berlin 1991.

13. Amphlett, C. B.: Inorganic Ion Exchangers. Elsevier Publishing Co, Amsterdam 1964.

14. Clearfield, A.: Inorganic Ion Exchange Materials. CRC Press, Inc., Boca Raton, Florida 1982. 
